\title{
O papel da cartografia na formação inicial do docente, seus limites e possibilidades na licenciatura em Geografia
}

\author{
The role of cartography in the teacher's initial training, its limits and possibilities in the \\ undergraduate licence in Geography
}

\author{
Dayana Aparecida Marques de Oliveira Cruz \\ Doutora em Geografia pela FCT/UNESP e Docente no IFSP/Registro, Brasil \\ d.dayana@hotmail.com \\ Mariana da Silva Ferreira \\ Doutora em Geografia pela PUC/MG e Docente na Educação Básica \\ do Estado de Minas Gerais, Brasil \\ marianamsf@yahoo.com.br
}

\begin{abstract}
Resumo
Este artigo discute o papel da linguagem cartográfica na formação inicial do docente, destacando limites e possibilidades. O fazer cartográfico mesmo estando ligado historicamente às classes dominantes se apresenta como possibilidade de ler e interpretar o mundo em seus diversos cenários cotidianos. Por meio de pesquisa bibliográfica o estudo corrobora para apresentar caminhos que possibilitem romper os limites impostos à Cartografia e apreendê-la como linguagem cuja contribuição para o ensino de Geografia corrobore para a formação do indivíduo com vistas a uma formação cidadã. Consideramos que os limites na formação do docente em Geografia quanto à linguagem cartográfica são impostos por uma prática que necessita de reflexão. Refletir sobre essa prática pedagógica passa por pensar a educação para a formação cidadã, em como a cartografia se apresenta na formação inicial do docente em Geografia e em metodologias da linguagem cartográfica que contribuam para fazer esse fim.
\end{abstract}

Palavras-chave: Geografia; Cartografias; Formação docente; Metodologias de ensino.

\begin{abstract}
This article discusses the role of cartographic language in the initial training of teachers, highlighting limits and possibilities. Even though it is historically linked to the dominant classes, Cartographic making presents itself as a possibility of reading and interpreting the world in its various daily scenarios. Through bibliographic research, the study corroborates to present paths that make it possible to break the limits imposed on Cartography and apprehend it as a language whose contribution to the teaching of Geography corroborates the formation of the individual with a view to a citizen formation. We consider that the limits in the teaching of Geography teachers regarding the cartographic language are imposed by a practice that needs reflection. Reflecting on this pedagogical practice involves thinking about education for citizen training, how cartography presents itself in the initial training of teachers in Geography and in methodologies of cartographic language that contribute to this end.
\end{abstract}

Keywords: Geography; Cartographies; Teacher training; Teaching methodologies 


\section{INTRODUÇÃO}

A cartografia é uma linguagem fundamental para a organização das sociedades, sobretudo no que diz respeito ao conhecimento, expansão e domínio dos territórios. Do mapa Ga-Sur, datado de 2.500 a.C, ao uso dos atuais recursos tecnológicos e aplicativos para smathphones, a cartografia passou por inúmeras transformações relacionadas ao desenvolvimento técnico das sociedades.

Concomitantemente, a cartografia é arte, ciência e técnica (JOLY, 2011, p. 8), suas representações são formas de saber socialmente construído que carregam diferentes visões de mundo e simbolismos (MARTINELLI, 2009, p. 8).

Se por um lado, o fazer cartográfico esteve historicamente ligado às classes dominantes, a legitimação de discursos de poder e ideologias, imbuídos de múltiplos significados políticos, econômicos e socioculturais (HARLEY, 2009, p. 2 e LACOSTE, 2012, p. 10), por outro lado, ele é uma possibilidade de leitura e interpretação do mundo, de apropriação e protagonismo do indivíduo na discussão dos fenômenos espaciais que impactam diretamente o cotidiano. Por isso, possui uma contribuição significativa na formação do cidadão.

Contraditoriamente, o uso da cartografia na educação básica é geralmente limitado às representações cartográficas como meras ilustrações durante as aulas de geografia ou como exemplos utilizados nos livros e materiais didáticos. Tal uso, diminui as possibilidades de reflexão sobre o mundo e sobre os fenômenos geográficos, caracterizando a cartografia apenas como um recurso ou ferramenta pedagógica.

Como romper os limites impostos à cartografia e apreendê-la como uma linguagem cuja contribuição ao ensino de Geografia corrobore para a formação cidadã do indivíduo? Essa é uma das perguntas basilares deste artigo. Nosso objetivo é discutir sobre a importância da cartografia na formação inicial do docente no curso de licenciatura em Geografia.

Este artigo está dividido em três partes. Na primeira, "Educação geográfica e formação cidadã: o que a cartografia tem a ver com isso?”, discutiremos o papel da cartografia no ensino de geografia e sua contribuição para a formação cidadã. Em seguida, “A cartografia na formação inicial do docente de Geografia" falaremos sobre as possibilidades de reflexão e incorporação da cartografia no curso de licenciatura em Geografia. Na terceira, “A linguagem cartográfica e a contribuição do uso de suas metodologias na formação cidadã” daremos ênfase ao fazer cartográfico a partir das geotecnologias, da cartografia tátil, e da cartografia subversiva como possibilidades para o protagonismo e a autonomia no ensino de Geografia. 


\section{EDUCAÇÃO GEOGRÁFICA E FORMAÇÃO CIDADÃ: O QUE A GEOGRAFIA TEM A VER COM ISSO?}

Segundo as considerações de Castellar (2001), a educação geográfica só é alcançada quando há preocupação com a formação do cidadão. Considerando o quadro atual da educação no Brasil, a autora defende a transformação didático-pedagógica, ética e estética do professor. Isso quer dizer que a formação cidadã deve ser, primeiramente, um dos principais objetivos na formação do professor, pois é essa formação que o levará a postura crítico-reflexiva necessária para formar outros cidadãos.

A formação cidadã é libertária, sobretudo na sociedade do consumo em que os interesses individuais se sobrepõem ao coletivo, devido a alienação do trabalho e a fetichização da mercadoria. Milton Santos (2013, p. 84), ao analisar o contexto nacional de redemocratização afirmou que a cidadania brasileira era incompleta, mutilada e atrofiada. $\mathrm{O}$ autor atribuiu tais características à falta de consciência dos indivíduos em relação ao seu papel social, sendo esta necessária para lutar coletivamente pelos direitos que, embora garantidos na legislação, eram constantemente ameaçados ou nem se quer colocados em prática. Na atualidade, tal afirmação continua vigorando por conta do avanço do neoliberalismo no país, da consequente fragilidade da democracia brasileira e do desmonte da educação em diferentes níveis de ensino.

Numa concepção tecnocrática de desenvolvimento, de uma mentalidade fordista periférica (na qual só se aproveitou do fordismo a produção em massa e estandartizada, a linha de montagem e a vigilância cronometrada sobre o trabalho, deixando-se de lado o aumento do poder aquisitivo, como precondição do consumo em massa), não apenas o professor foi desprestigiado, como o foram, mais ainda, a formação para a cidadania e as humanidades (VESENTINI, 2013, p. 237).

Neste cenário caótico, ao invés da atuação democrática do cidadão, emerge a figura do consumidor mais-que-perfeito, que também aceita ser chamado de usuário (SANTOS, 2013, p. 88). Temos, portanto, um espaço sem cidadãos, no qual os indivíduos atribuem os problemas sociais às escolhas individuais, são alheios à coletividade e afeitos à meritocracia, pois sua capacidade de refletir sobre a realidade é parcial. O consumidor chega a naturalizar a crise e a miséria, conforme discute Straforini (2011, p. 18).

É possível reverter este cenário? Um ponto de partida para refletir sobre as possibilidades de reversão passa pelo papel da escola enquanto instituição e pela formação e práxis do docente. Ela depende da consciência que este tem sobre o papel da disciplina na formação do cidadão. No caso da Geografia, "considerando que as práticas cotidianas são espaciais, o conhecimento geográfico é importante para a vida cotidiana. Afinal, compreender o mundo e ser sujeito de sua vida é a condição para viver com dignidade" (CALLAI, 2010, p. 16). Portanto, 
é preciso formar uma consciência espacial para a prática da cidadania. Consciência espacial como sinônimo de perceber o espaço como um elemento importante de nossa organização social, presente no cotidiano. Cidadania entendida aqui como uma pessoa que, sabendo de seu mundo, procura influenciá-lo, organizando-se coletivamente na busca, não só dos seus direitos, mas também lutando por uma organização da sociedade mais justa e democrática (KAERCHER, 2013, p. 225).

Sem essa consciência sobre o papel da Geografia, o docente acaba se limitando à reprodução de materiais didáticos e a realização de um trabalho pedagogicamente precário.

Como a práxis do docente pode ser emancipadora e contribuir para a formação do cidadão se a formação inicial do docente não tiver este mesmo intuito? A formação do docente é basilar para o exercício da cidadania, pois, mesmo no contexto da sociedade do consumo, a geografia, "não pode e não deve permitir que os alunos saiam da escola reproduzindo um sistema que os sufoca" (STRAFORINI, 2001, p.27).

Através da compreensão dos fenômenos espaciais por meio de conceitos e categorias da ciência geográfica, a contribuição da Geografia para a formação cidadã relaciona-se à leitura e interpretação do mundo, na qual a linguagem cartográfica está incluída. O papel e importância da Geografia para a vida dos alunos está em fornecer bases e meios para desenvolver e ampliar a compreensão dialética do papel do espaço nas práticas sociais. Tarefa árdua dada a complexidade da espacialidade atual que decorrente do processo de mundialização da sociedade torna-se fluida e sem limites definidos. (CAVALCANTI, 1998, p.11).

A linguagem cartográfica possui signos próprios, que através de suas representações (mapas, plantas, cartas, maquetes, globos), sejam elas analógicas ou tecnológicas, indicam a espacialização dos fenômenos geográficos. Os fenômenos representados só podem ser compreendidos em sua totalidade a partir de conceitos e categorias do arcabouço teórico-epistemológico da Geografia. Por um lado, as representações cartográficas não são isentas da interpretação conceitual dos fenômenos espaciais. Por outro, as discussões no âmbito da Geografia e do espaço geográfico sem a leitura da disposição e distribuição desses fenômenos, diminuem as potencialidades de interpretação da realidade, de desmistificação dos discursos de poder e das ideologias, e do desvelamento da naturalização dessas representações (LACOSTE, 1988, p. 9; HARLEY, 2009, p. 2; SEEMANN, 2012, p. 145).

A cartografia como linguagem é trabalhada por diversos autores. Alguns deles, como Harley (2009, p. 2) não se preocupa em afirmar se essa linguagem é metafórica ou não, mas que o conceito de linguagem se traduz à prática histórica.

As relações dialéticas entre imagem e poder não podem ser dissociadas dos procedimentos destinados a avaliar o conhecimento topográfico bruto dos mapas e não há teste para verificar suas tendências ideológicas. Compreendidos como saber assimilado a um poder, os mapas são explorados sob três ângulos: a universalidade dos contextos políticos na história da cartografia; a maneira pela qual o exercício do poder estrutura o conteúdo dos mapas, e a 
maneira pela qual a comunicação cartográfica, num nível simbólico, pode reforçar este poder por intermédio do conhecimento cartográfico (HARLEY, 2009, p. 3).

Nesse sentido "a mensagem cartográfica também pode ser uma mensagem de interpretação e de comunicação científica [...] o mapa não é neutro.” (JOLY, 2011, p. 9). O reforço desse poder por intermédio do conhecimento cartográfico é transmitido pelo sistema de conhecimento que propõe uma certa imagem do mundo. Essa imagem do mundo pode ser observada na naturalização de mapas, projeções cartográficas e escolha de simbologias.

\section{A CARTOGRAFIA NA FORMAÇÃO INICIAL DO DOCENTE}

O conhecimento específico da linguagem cartográfica contribui para a nitidez quanto à seleção das informações, das variáveis visuais e das escolhas mais adequadas para a representação de um determinado fenômeno (MARTINUCCI, 2016, p. 44). É necessário ainda ter consciência do contexto de criação das representações cartográficas. É o contexto, segundo Harley (2009, p. 9) que nos permite discernir as influências (política, religiosa e social) e circunstâncias sobre as quais os mapas foram elaborados.

Os conhecimentos específicos, geográficos ou cartográficos não são suficientes para que o indivíduo se torne um cidadão. No processo de formação do cidadão, é preciso considerar as heterogeneidades e as diferentes formas de aprendizagens, o contexto socioeconômico, as diversidades, as singularidades dos lugares, das pessoas e as deficiências. Daí a relevância de diferentes formas de cartografar e reconhecer o protagonismo e a autonomia dos indivíduos, como é o caso da cartografia social, da cartografia tátil, das cartografias subversivas, do uso das geotecnologias, entre outras formas de representação do espaço.

Ao elaborar uma representação cartográfica, o indivíduo passa a refletir sobre algumas questões e diferentes níveis de complexidade, tais como: Por quê nem todas as informações de determinado espaço estão representadas? Como tomar as decisões que determinam o que deve aparecer no mapa? Quais as implicações dessas escolhas? O que deve ser considerado na leitura de uma representação cartográfica? Como os fenômenos espaciais atingiram tal distribuição?

Embora os cartógrafos estejam cientes de que existem distorções, desvios, variações e abusos em relação à realidade, existem poucos escritos sobre esses aspectos, principalmente sobre as implicações políticas e sociais do que eles representam (HARLEY, 2009, p. 9). Há ainda, o silêncio nos mapas, como é o caso dos mapas coloniais da América do Norte do século XVIII, que também são considerados como discriminatórios contra os povos indígenas (HARLEY, 2009, p. 9).

Se a bibliografia especializada pouco trata sobre estes aspectos tão relevantes, na sala de aula essa discussão não pode ser ignorada, sobretudo no processo de formação inicial do docente. Mas 
como abordar uma discussão tão complexa apenas nas disciplinas específicas de cartografia? Haveria tempo hábil para tal discussão?

Concordamos que como as demais disciplinas específicas do curso de licenciatura em Geografia, a disciplina de cartografia deve abranger conhecimentos específicos, mas não é só isso! Nas disciplinas do curso de Geografia, os conceitos e categorias relativos à ciência geográfica estão sempre presentes, por quê a linguagem cartográfica que propicia a leitura e interpretação dos fenômenos geográficos não pode estar também? Nos referimos ao uso das representações cartográficas para além do exemplo didático, incluímos a reflexão sobre o fazer cartográfico, o contexto de elaboração das representações cartográficas, os aspectos históricos e geográficos que contribuíram para a conformidade da espacialização dos fenômenos, bem como o uso das metodologias de representação cartográfica que admitam diferentes formas de cartografar e apoiem o protagonismo e a autonomia do sujeito.

Este é, sem dúvida, um grande desafio! Em primeiro lugar, porque existe um afastamento entre Geografia e Cartografia. Em segundo lugar, porque na prática pedagógica, os docentes possuem algumas dificuldades básicas em relação ao uso da linguagem cartográfica, o que poderia ser minimizado se ela estivesse presente em todo o processo de formação inicial dos docentes.

Em pesquisa realizada por Ivanilton de Oliveira (2010, p. 129) com 47 professores da rede pública de Goiânia, 91\% dos professores responderam que os estudantes apresentam dificuldades, sendo que quase a metade possui aversão à cartografia; $66 \%$ dos professores responderam ter dificuldades com o conteúdo de Cartografia (projeções, imagens de satélite e escala) e 50\% dos professores nunca utilizaram geotecnologias.

Uma das possibilidades que a linguagem cartográfica permite é o rompimento com a abordagem hierárquica e rígida das escalas geográficas, a partir de círculos concêntricos que não demonstram a complexidade e a inter-relação entre elas. O mundo não é fragmentado e as escalas geográficas não podem ser consideradas isoladamente (CALLAI, 2005, p. 231; STRAFORINI, 2008, p. 92). Compreender, portanto, a interdependência entre as escalas geográficas e como os fenômenos se materializam no lugar é fundamental para o desenvolvimento do raciocínio geográfico. Straforini (2008) ao citar os Parâmetros Curriculares Nacionais de 1998, afirma que as escalas espaciais não devem mais ser trabalhadas do nível local ao mundial hierarquicamente e sim dentro da perspectiva de inter-relação entre elas. A Base Nacional Comum Curricular para os anos iniciais do ensino fundamental na unidade temática "Conexões e escalas" atenta para:

[...] a articulação de diferentes espaços e escalas de análise, possibilitando que os alunos compreendam as relações existentes entre os fatos nos níveis local e global [...] precisam entender as interações multiescalares existentes entre sua vida familiar, seus grupos e espaços de convivência e as interações espaciais mais complexas. (BRASIL, 2017, p. 360). 
A seguir, apresentaremos algumas possibilidades de uso das metodologias relacionadas à linguagem cartográfica que contribuem para a formação inicial docente.

\title{
4. A CARTOGRAFIA NA FORMAÇÃO INICIAL DO DOCENTE
}

\subsection{O uso das geotecnologias}

As geotecnologias trazem novas perspectivas, pois os estudantes podem trabalhar com informações mais precisas e em diferentes escalas geográficas, sobretudo em relação à escala de vivência dos alunos, que geralmente não aparece nos livros didáticos. Essa perspectiva é reforçada pois a "[...] disponibilidade gratuita de imagens de satélite e softwares de geoprocessamento criaram possibilidades para a inserção de geotecnologias na educação básica que permite o aluno localizar, analisar, interpretar e correlacionar informações espaciais." (SOUSA; SOUSA, 2014 p.2).

A modernização e as técnicas da contemporaneidade têm desenvolvido novos instrumentos para o mapeamento da superfície terrestre.

\begin{abstract}
O uso dos satélites permite controlar e gerenciar a comunicação na escala do planeta. A comunicação atingiu o conjunto do espaço terrestre: basta um satélite e uma rede de pontos para transmitir toda informação desejada. O planeta pode ser reorganizado de tal maneira que nenhum ponto fique isolado e, dessa forma, o espaço é perfeitamente dominado (RAFFESTIN, 1993, p. 213).
\end{abstract}

Sensoriamento Remoto e Geoprocessamento estão modificando a aquisição de imagens, sua construção, armazenamento, publicação e o acesso às representações cartográficas diversas. Com isso, há um aumento expressivo do número de usuários de mapas digitais e da cibercartografia. A combinação de diferentes elementos como sons, vídeos, textos, gráficos e animações propicia uma leitura mais próxima da realidade dos fenômenos espaciais. A cartografia multimídia é uma nova linguagem de comunicação. A partir da interatividade, o aluno tem uma participação propositiva e não mais de recepção passiva das informações (GOMES, 2010, p. 118). A interatividade propicia um trabalho mais efetivo a partir da diferença nos ritmos de aprendizagem dos alunos. E também explora outros recursos além dos tradicionalmente utilizados (MELO, 2006, p. 68).

Dentre as possibilidades de aplicação do sensoriamento remoto no ensino, estão: análise temporal dos fenômenos, visualização tridimensional do recorte territorial, e estímulo à interdisciplinaridade a partir do estudo do meio.

É preciso um olhar crítico e consciente do professor em desmitificar as imagens orbitais como verdades absolutas e sem questionamentos, pois em alguns lugares as informações espaciais estão representadas com excelente qualidade inclusive em terceira dimensão e com a visão de rua (Google Street View) sem quaisquer interferências de cobertura de nuvens e, em contrapartida, outros ambientes da superfície terrestre apresentam omissão ou baixa resolução espacial, dificultando a visualização dos objetos e fenômenos geográficos (SOUSA, 2018, p. 7). 
Para a autora, isso pode ser explicado devido a existência de interesses culturais, econômicos, políticos e sociais como os mecanismos de estratégias e de controle utilizados por órgãos governamentais.

De acordo com Ferreira (2014) somos permeados por perguntas espaciais em nossas cenas cotidianas ao ter que tomar decisões complexas a partir da escolha de diversas possibilidades oferecidas pelo espaço geográfico. Para tomar essas decisões, de por onde e como ir para chegar a um destino, o autor cita que primeiramente é realizada uma análise geoespacial da cidade. Sendo assim, nas cenas do cotidiano consideradas a partir do deslocamento espacial a análise é desencadeada por um sistema cerebral composto por informações geográficas representadas internamente como mapas mentais.

Nem sempre nos deslocamentos podemos contar com nossos mapas mentais. Nesse sentido a análise geoespacial ganha um novo significado com aplicativos que utilizam do Global Position System (GPS) como fundamento para colaborar nessa escolha. Observar essas ferramentas e suas utilizações são possibilidades para um trabalho significativo tanto para o docente quanto para o aluno. Este poderá ser despertado pelo interesse em analisar dados da sua vivência e sair do trabalho que geralmente direciona para atividades mecânicas. "Cabe a Geografia escolar desenvolver e incluir linguagens que permitam ao estudante compreender o espaço geográfico contemporâneo, de maneira articulada com todas as suas dimensões e contradições [...]” (SOUSA; JORDÃO, 2015, p. 152).

Entre os exemplos de aplicativos gratuitos que se configuram como possibilidade estão: LandscapAR para simular relevo a partir de curvas de nível; Google Earth para permitir diversos modos de visualização (horizontal, obliqua e vertical) e também o acesso a imagens de diferentes períodos o que permitirá a observação da dinâmica espacial, entre outros.

As geotecnologias possibilitam a adoção de metodologias participativas para o engajamento político e social de comunidades tradicionais e grupos sociais fragilizados economicamente na luta por seus direitos. A cartografia social abre possibilidades para compreender as multiescalaridades dos processos geográficos e o papel do indivíduo e da comunidade no espaço geográfico (GOMES, 2017, p. 98).

O uso das geotecnologias precisa ser acompanhado pela reflexão sobre os métodos, meios e formas pelas quais as imagens e representações cartográficas são adquiridas e elaboradas. O olhar crítico do indivíduo sobre o seu papel no mundo como mapeador e como sujeito mapeado implica na consciência sobre as relações de poder, sobre os interesses, sobre o silenciamento e sobre os discursos das representações cartográficas. Neste aspecto, ressaltamos a produção audiovisual de Ernesto Carvalho (2016) denominada "Nunca é noite no mapa".

A seguir, o trecho da narração em que o locutor descreve uma pequena parte do processo de mapeamento do Google Street View, reconhecendo-se como parte deste, porém sem o devido 
protagonismo. A produção audiovisual remete também à necessidade de considerar os processos e dinâmicas que resultam na transformação das paisagens, a partir do caso de Recife/PE.

Eu estou dentro do mapa. O mapa não se importa se eu estou dentro dele ou não, mas eu estou
dentro do mapa. O mapa é indiferente, livre! O mapa não precisa de pernas, de asas, o mapa.
O mapa não anda, nem voa, nem corre, não sente desconforto, não tem opinião. Nunca chove
dentro do mapa e não há vento no mapa. No mapa não há contramão, nem velocidade. Pro
mapa não tem engarrafamento, nem direção. O mapa é um olho desincumbido de um corpo.
Eu estou dentro do mapa, em algum lugar, mesmo que eu tente me esconder, o mapa me
encontra e me contém (CARVALHO, 2016 - Trecho da narração do vídeo "Nunca é noite no
mapa").

\subsection{A cartografia tátil para incluir e emancipar}

Como mencionado anteriormente, é mister que a linguagem cartográfica seja trabalhada a partir de diferentes abordagens e metodologias, visando a inclusão, o protagonismo e a autonomia dos indivíduos. A cartografia tátil é uma das metodologias capazes de abranger esses aspectos, por isso deve estar incluída no processo de formação de professores, seja ele inicial ou continuado.

Ademais, no cotidiano da sala de aula, apesar da necessidade e da importância da educação inclusiva, Chaves e Nogueira (2011, p. 281) argumentam que há falta de informação dos professores, por isso muitos chegam a desacreditar da capacidade dos estudantes com deficiência. A falta de informação, que é reflexo da formação inicial e continuada ineficaz, somada a inexistência de recursos ou de materiais que atendam a todos os estudantes, conforme discute Freitas (2011, p. 224) tornam a prática do ensino de geografia excludente. Tal exclusão é parte da herança da concepção colonial imbricada na estrutura educacional brasileira a qual trata o "diferente" como alguém que é excluído da "normalidade" (CHAVES e NOGUEIRA, 2011, p. 282). A diferença traz novas potencialidades de ampliação dos horizontes explorados no ensino de Geografia, mas, para que essas potencialidades se revertam em aprendizado, autonomia e protagonismo dos indivíduos, é preciso que a formação inicial do docente contemple e reflita sobre elas. Entendemos que o uso da cartografia como linguagem é um caminho para tal reflexão.

A cartografia tátil contribui para a inclusão dos estudantes com deficiência visual, sejam eles cegos ou com baixa visão (pessoas que têm trinta por cento ou menos da capacidade de enxergar) (ALMEIDA, 2009), que segundo o IBGE (2010) são 6,5 milhões de brasileiros. Esses indivíduos dependem da apreensão tátil para acessar informações sobre os fenômenos geográficos e, consequentemente, formar conceitos espaciais a partir delas.

Além da inclusão, a cartografia tátil contribui para a didática multissensorial, que expande o uso dos sentidos, por isso, ela não se limita apenas à aplicação na educação especial, suas técnicas podem ser utilizadas em aulas com estudantes de qualquer perfil ou idade (CARMO, 2009, p. 77). 
Existem diferentes técnicas para a elaboração de representações táteis (técnica com alumínio, reprodução em máquinas Thermoform, técnica com porcelana fria, impressão em papel microcapsulado, impressão 3D, etc.). Dentre elas, a técnica de colagem permite a elaboração de mapas táteis a partir do uso de técnicas artesanais e utilização de materiais de fácil acesso e de baixo custo (Figura 1), como materiais de papelaria, de costura, artesanato, recicláveis entre outros. “A colagem permite uma combinação de materiais e, consequentemente, uma gama ampla de variáveis gráficas contidas em um mesmo mapa, além de ser viável atingir maiores elevações" (ALMEIDA, 2009, p. 136).

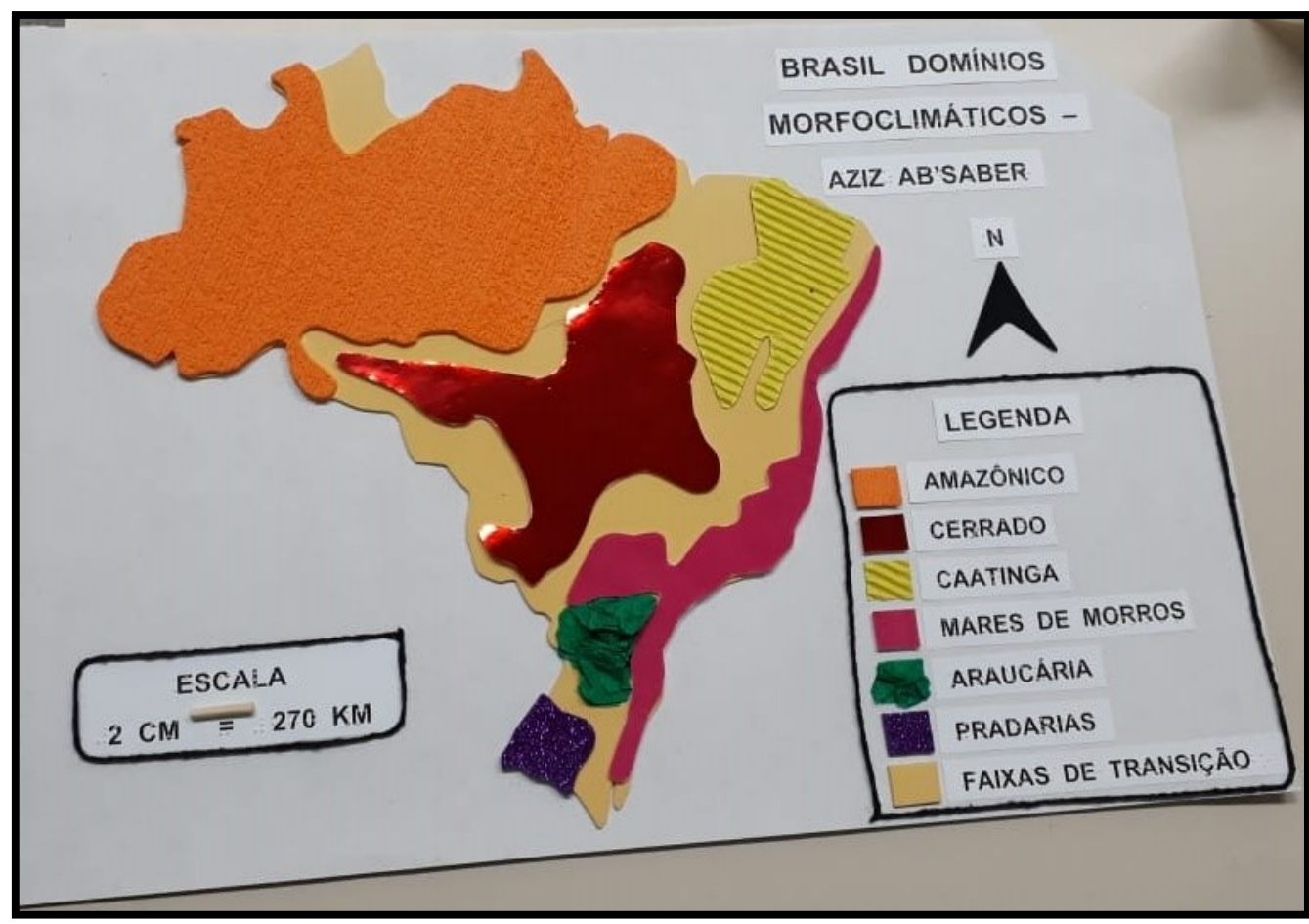

Figura 1: Mapa tátil elaborado utilizando a técnica de colagem Elaborado por Dayana A. M. De Oliveira Cruz

É fundamental destacar que apesar das possibilidades de fácil acesso aos materiais para a elaboração dos mapas e outras representações cartográficas táteis por meio da técnica de colagem, para que o professor possa trabalhar de forma autônoma na elaboração destes materiais, é imprescindível o conhecimento em cartografia. Neste caso, as escolhas quanto às variáveis, às informações, os materiais e os elementos do mapa só podem ser tomadas após o processo de reflexão sobre os objetivos das representações cartográficas. Ademais, a elaboração de mapas táteis requer, muitas vezes, uma simplificação ou generalização da informação geográfica, pois os mapas táteis “precisam de um grau de generalização com omissões, exageros e distorções nunca imaginados pelo cartógrafo. A cartografia tátil precisa de outros conceitos e regras, com técnicas distintas para a produção de mapas" (ALMEIDA, 2009, p. 125). 
Mas, como refletir sobre os objetivos de uma representação cartográfica, se o docente não tiver conhecimento sobre o fenômeno representado ou sobre a semiologia gráfica? Como elaborar o próprio mapa considerando o conhecimento ou os temas trazidos pelos estudantes, se o docente não sabe por onde começar?

É na formação de professores que a postura autônoma precisa ser estimulada para que haja a capacidade de mobilizar os conhecimentos sistematizados de acordo com as singularidades de cada ambiente escolar. Isso porque a mera reprodução de conteúdo, de materiais ou de técnicas, baseadas na homogeneização em nada contribuirá para a formação de cidadãos.

\subsection{Interdisciplinaridade e subversão: intersecção entre cartografia e arte}

A cartografia subversiva é uma contracartografia crítica ao modelo normativo, convencionado e euclidiano das representações espaciais. Ela questiona, portanto, o fazer cartográfico oficial e excludente, que visa o exercício de poder e o controle sobre o espaço. A partir da cartografia subversiva são propostas alternativas utilizadas nas representações dos espaços com um viés de construção sociocultural, pluralista e multivocal, e releitura dos parâmetros e convenções tradicionalmente utilizados na cartografia (SEEMANN, 2012, p. 140).

A cartografia subversiva é uma metodologia utilizada também nas artes como é o caso do "Mapa Invertido da América do Sul" do artista uruguaio Joaquin Torres-García, de "Bomb after Bomb: A Violent Cartography" da artista Elin O'Hara Slavick, ou o "Sistema Uniplanetário" do artista Alex Flemming (Figura 2).

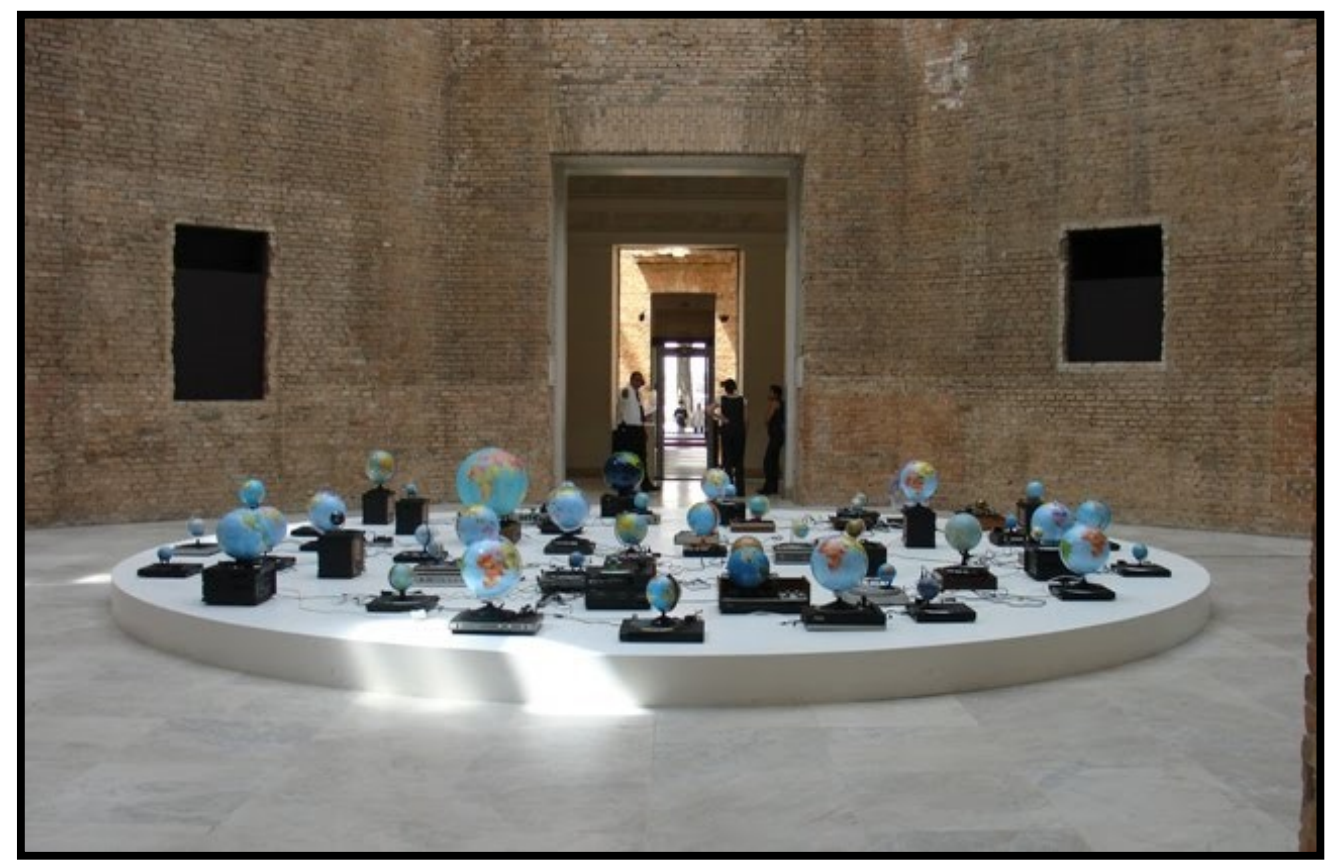

Figura 2: "Sistema Uniplanetário" do artista Alex Flemming.

Fonte: https://patrialais.blogspot.com/2010/01/arte-alex-flemming.html, acesso em 05/04/2020 
No ensino de Geografia, utilizá-la requer conhecimento das convenções tradicionais da cartografia e de suas implicações na visão política e organização da sociedade para questioná-la. Por outro lado, ela contribui para a emancipação do indivíduo por meio da possibilidade de expressão de sua criticidade e subjetividade em relação aos fenômenos espaciais e dinâmicas socioespaciais contemporâneas. A cartografia subversiva caracteriza-se como uma metodologia contemporânea inovadora com amplas possibilidades de uso interdisciplinar, envolvendo diferentes temáticas e níveis de reflexão sobre o fazer cartográfico.

O artigo escrito por Cruz (2020, p. 639) mostra o resultado de uma experiência realizada com os estudantes do primeiro ano do curso de licenciatura em geografia da Universidade Federal de São Carlos (UFSCar/Sorocaba) em 2019. O uso da cartografia subversiva como metodologia utilizada pela autora mostrou-se promissor no debate sobre a cartografia e outros temas que raramente são abordados na disciplina, sobretudo em relação à interface com a geopolítica.

\section{CONSIDERAÇÕES FINAIS}

A linguagem cartográfica é fundamental para o desenvolvimento do pensamento espacial. A partir dela, o indivíduo tem a possibilidade de ler e interpretar o mundo em que vive, e consequentemente, pode se reconhecer como cidadão. Mas, para que no ensino de Geografia e a formação cidadã possa ser uma realidade, é preciso que a formação inicial do docente tenha o mesmo objetivo.

Defendemos ao longo do artigo que a cartografia deve ser apreendida como linguagem desde a formação inicial do futuro docente, no entanto, é necessário afirmar também que a cartografia não se restringe ao seu contexto de formação inicial, pois ela deve fazer parte da formação continuada, principalmente no que tange à reflexão enquanto linguagem e às diferentes metodologias de representação cartográfica aplicadas ao ensino de Geografia. Para nós, esse é o caminho que torna possível a contribuição da cartografia para a leitura e interpretação dos fenômenos espaciais e para a formação cidadã. Ser cidadão inclui conhecer o espaço geográfico e identificar na coletividade o seu papel no mundo, processo no qual a linguagem cartográfica e suas metodologias de representação espacial, sejam elas convencionais ou não (cartografia tátil, cartografia social, uso das geotecnologias, mapeamentos comunitários e cartografias subversivas) têm muito a contribuir.

Os limites da cartografia na formação do docente são impostos por uma prática ausente da reflexão que geralmente distancia o cartógrafo do usuário de seu produto final e da compreensão de sua perspectiva na concepção do mesmo. As possibilidades remetem à práxis e as constantes reflexões sobre os objetivos da formação em geografia. Se queremos que na educação básica os estudantes compreendam por meio do ensino de Geografia o mundo em que vivem e assim possam 
agir conscientemente nele exercendo sua cidadania, necessitamos que o professor seja consciente do papel social de sua profissão, da ciência geográfica e das linguagens que contribuem para a leitura crítica dos fenômenos espaciais, como é o caso da cartografia.

Caso contrário, estaremos perpetuando o uso estanque das representações cartográficas apenas como localização dos objetos espaciais. Na prática, percebemos que nos livros e materiais didáticos em que há proposta de leitura de textos sobre os temas relacionados à geografia, os mapas que vêm acompanhados são tratados apenas como ilustrações complementares, podendo ser até mesmo dispensáveis. Os estudantes, muitas vezes, observam os mapas, mas não os leem! Leem os textos, mas não são estimulados a compreender as legendas e seus signos. Que a formação inicial do docente esteja comprometida em debater e refletir sobre o papel da leitura do mundo a partir da linguagem cartográfica. Relegá-la às disciplinas específicas durante a graduação é diminuir seu potencial para a formação do futuro docente.

Portanto, atitudes como estabelecimento de relações entre a cartografia e os conteúdos geográficos são base para a compreensão dos conceitos, considerando uma evolução técnica, inclusiva, interdisciplinar e subjetiva da ciência cartográfica.

\section{REFERÊNCIAS}

ALMEIDA, R. A. A cartografia tátil no ensino de geografia: teoria e prática. In: ALMEIDA, R. A (org). Cartografia escolar. 2. ed. São Paulo: Contexto, 2009, p. 119-144.

BRASIL. Base Nacional Comum Curricular. Brasília: MEC, 2017.

CALLAI, H. C. A geografia ensinada: os desafios de uma educação geográfica. MORAIS, E. M. B; MORAES, L. B (org). Formação de professores: conteúdos e metodologias no ensino de Geografia. Goiânia: NEPEG, 2010, p. 15-38.

CALLAI, H. C. Aprendendo a ler o mundo: a geografia nos anos iniciais do ensino fundamental. In: Caderno Cedes. Campinas, v. 25, n. 66, p. 227-247, 2005.

CARMO, W. R. Cartografia tátil escolar: experiências com a construção de materiais didáticos e com formação continuada de professores. São Paulo: Universidade de São Paulo. 195 f. Dissertação (Mestrado em Geografia Física). 2009.

CASTELLAR, S. V. A cartografia e a construção do conhecimento em contexto escolar. In: ALMEIDA, R. D (org). Novos rumos da cartografia escolar: currículo, linguagem e tecnologia. São Paulo: Contexto, 2001, p. 121-136.

CARVALHO, Ernesto. Nunca é noite no mapa. 2016. Disponível em: https://vimeo.com/175423925, acesso em 24 de abril de 2020.

CAVALCANTI, Lana de S. Geografia, escola e construção de conhecimentos. 16 ed. Campinas,SP: Papirus, 1998. 
CHAVES, A. P. N; NOGUEIRA, R. E. A inclusão de estudantes cegos na escola: um campo de debate e reflexão no ensino de Geografia. In: FREITAS, M. I. C; VENTORINI, S. E. (org). Cartografia tátil: orientação e mobilidade às pessoas com deficiência visual. Jundiaí: Paco Editorial, 2011, p. 279-302.

CRUZ, D. A. M. O. As cartografias subversivas e as possibilidades de diálogo com a (geo)política: contribuições para a emancipação na formação em geografia. Revista Brasileira de Educação em Geografia, Campinas, v. 10, n. 19, p. 629-640, 2020.

FERREIRA, M. C. Iniciação à análise geoespacial: teoria, técnicas e exemplos para geoprocessamento. São Paulo: Editora Unesp, 2014.

FREITAS, M. I. C. Cartografia tátil e a formação continuada de professores do ensino fundamental: contribuições para uma escola inclusiva. In: FREITAS, M. I. C; VENTORINI, S. E. (org). Cartografia tátil: orientação e mobilidade às pessoas com deficiência visual. Jundiaí: Paco Editorial, 2011, p. 221-250.

GOMES, M. F. V. B. Cartografia social e geografia escolar: aproximações e possibilidades. Revista Brasileira de Educação em Geografia. Campinas, vol. 7, n. 13, p. 97-110, 2017.

GOMES, S. A. Cartografia multimídia: possibilidade para a produção de novos conhecimentos geográficos. Brazilian Geographical Journal: Geosciences and humanities research. n. 1., 2010, p. 116-135.

HARLEY, B. Mapas, saber e poder. Confins [Online], n. 5, 2009. Disponível em: http://journals.openedition.org/confins/5724, acesso em 01/04/2019.

JOLY, Fernando. A cartografia. 14 ed. Campinas, SP: Papirus, 2011.

KAERCHER, N. A. O gato comeu a geografia crítica? Alguns obstáculos a superar no ensinoaprendizagem de geografia. In: PONTUSCHKA, N. N; OLIVEIRA, A. U (orgs). Geografia em perspectiva. 4. ed. São Paulo: Contexto, 2013, (p. 221-231)

LACOSTE, Y. A Geografia - isso serve, em primeiro lugar para fazer a guerra. Campinas: Papirus, 1988.

MARTINELLI, M. Mapas da Geografia e Cartografia Temática. 5. ed. São Paulo: Contexto, 2009.

MARTINUCCI, O. S. Geografia, semiologia gráfica e coromética. Mercartor. Fortaleza: Universidade Federal do Ceará, v. 15, n. 3, p. 37-52, 2016.

MELO, A. A. Atlas geográfico escolar: aplicação analógica e digital no ensino fundamental. Tese (Doutorado em Geografia). Universidade Federal do Rio de Janeiro. Programa de Pós-Graduação em Geografia. 305 f. Rio de janeiro, 2006.

OLIVEIRA, E. A.; OLIVEIRA, R. C. S. O uso do aplicativo LandscapAR como recurso pedagógico para o ensino de Geografia. Geosaberes, Fortaleza, v. 10, n. 22, p. 100 - 114, set. 2019. ISSN 2178 0463. Disponível em: <http://www.geosaberes.ufc.br/geosaberes/article/view/805>. Acesso em: 03 mar. 2020.

OLIVEIRA, I. J. A cartografia na formação do professor de Geografia: análise da rede pública municipal de Goiânia. In: MORAIS, E. M. B; MORAES, L. B (org). Formação de professores: conteúdos e metodologias no ensino de Geografia. Goiânia: NEPEG, 2010, p. 123-136. 
RAFFESTIN, C. Por uma geografia do poder. São Paulo: Editora Ática, 1993.

RICHTER, D. Raciocínio geográfico e mapas mentais: a leitura espacial do cotidiano por alunos do ensino médio. Presidente Prudente: Universidade Estadual Paulista. 320 f. Tese (Doutorado em Geografia), 2010.

SANTOS, M. O espaço do cidadão e outras reflexões. 2. ed. Brasília: Fundação Ulisses Guimarães, 2013.

SEEMANN, J. Subvertendo a cartografia escolar no Brasil. Revista Geografares. n. 12, p. 138-174, 2012.

SOUSA, I. B. Geotecnologias aplicadas ao ensino de cartografia: experiência com o Google Earth e o GPS no ensino fundamental II. Pesquisar. Florianópolis: UFSC, v.5, n.7, p. 1-17, 2018.

SOUSA, I. B; JORDÃO B. G. F. Geotecnologias como recursos didáticos em apoio ao ensino de cartografia nas aulas de Geografia do ensino básico. Caminhos de Geografia. Uberlândia: UFU, v. 16, n. 53, p. 150-163, 2015.

SOUSA, I. B; SOUSA, G. (2014). A formação do professor de geografia e as geotecnologias no ensino de cartografia: novos desafios na educação básica. Disponível em: $<$ https://www.researchgate.net/publication/280319199 A FORMACAO DO PROFESSOR D E GEOGRAFIA E AS GEOTECNOLOGIAS NO ENSINO DE CARTOGRAFIA NOVOS D ESAFIOS NA EDUCACAO BASICA >. Acesso em: 15 fev. 2020.

STRAFORINI, R. Ensinar geografia nas séries iniciais: o desafio da totalidade mundo. Dissertação (mestrado em Geografia). UNICAMP. Instituto de Geociências. 150 f. Campinas: s.n., 2001.

STRAFORINI, R. Ensinar geografia nas séries iniciais: o desafio da totalidade mundo. 2ed. São Paulo: Annablume, 2008.

VESENTINI, J. W. A formação do professor de geografia - algumas reflexões. In: PONTUSCHKA, N. N; OLIVEIRA, A. U (orgs). Geografia em perspectiva. 4. ed. São Paulo: Contexto, 2013, p. 235-240. 